\title{
ATHEROGENIC INDEX OF PLASMA IN MYOCARDIAL INFARCTION IN RURAL POPULATION OF MARATHWADA REGION
}

Dr. Ganesh D Ghuge, Dr. Rahul Zine.

1. Associate Professor, Department of Biochemistry, Rural Medical College, Loni, Ahmednagar, Maharashtra.

2. Assistant Professor, Department of Biochemistry, Indian Institute of Medical Sciences and Research, Jalna, Maharashtra.

\section{CORRESPONDING AUTHOR}

Dr. Ganesh D Ghuge,

Associate Professor, Department of Biochemistry,

Rural Medical College, Loni, Taluka- Rahata,

District- Ahmednagar, Maharashtra 413736.

E-mail: dr_ganeshghuge@yahoo.com,

Ph: 91-9850694964, 91-7588846300.

ABSTRACT: BACKGROUND: Extensive research work by mankind over several decades has concluded that cure as well as the treatment of CAD is very difficult hence attention towards prevention of such ischemic events is of utmost importance. METHODS: The present study was conducted with an aim to study the Atherogenic Index and various lipid levels of plasma in Acute Myocardial Infarction (AMI) and to compare lipid profile and Atherogenic Index of plasma in the patients of Myocardial Infarction with healthy controls. RESULTS: A total of 150acute Myocardial Infarction (AMI) patients for the study were selected from the Medicine Ward, ICU, and OPD. Normal healthy person of matched number, age and sex of the study group were used as control. Serum cholesterol, TGVLDLc, LDLc and AIP were significantly higher in AMI patients as compared. CONCLUSION: Atherogenic Index of plasma is very useful research tool to assess the effect of risk factors pertaining cardiovascular diseases.

KEYWORDS: Atherogenic index, lipid profile, myocardial infarction, triglycerides.

INTRODUCTION: Coronary Artery diseases (CAD) are the most frequent cause of death in developing country like India (1). Extensive research work by mankind over several decades has concluded that cure as well as the treatment of CAD is very difficult hence attention towards prevention of such ischemic events is of utmost importance. The famous Framingham study firmly established cholesterol as an important risk factor for CAD and now we have a clear perception of the inter-relationship between serum lipids, Atherosclerosis \& Ischemic Heart Disease (IHD) (2). Therefore research laboratories have made conflicting claims to the helpful serum lipid level predictor for detecting and managing IHD with emphasis on the measurement of levels of serum cholesterol, lipoproteins and Triglycerides. The Atherogenic index of plasma defined as log (TG / HDLc) has recently been proposed as a marker of plasma atherogenicity (3). It is increased in people at higher risk of CAD .Tan et al used the AIP, calculated as log (TG / HDLc) with TG and HDLc expressed in molar concentration(4). Value of AIP corresponds closely to those of esterification rate in apo-B-lipoprotein - depleted plasma and to lipoprotein particle size. AIP reflects the delicate metabolic interactions within the whole lipoprotein complex (3). The present study was conducted with an aim to study the Atherogenic Index and various lipid levels of plasma in Acute Myocardial Infarction (AMI) and to compare lipid Profile and Atherogenic Index of plasma in the patients of Myocardial Infarction with healthy controls.

Journal of Evolution of Medical and Dental Sciences/Volume1/ Issue3/July-Sept 2012 Page 237 
MATERIALS AND METHODS: The present study was conducted in Department of Biochemistry, S R T R Medical College Ambejogai, Maharashtra, India. A total of 150 Acute Myocardial Infarction (AMI) patients for the study were selected from the Medicine Ward, ICU, and OPD. Normal healthy person of matched number, age and sex of the study group were used as control.

COLLECTION OF SAMPLE: The fasting blood sample was obtained in plain bulb from the study group and control group from antecubital vein with all aseptic precaution.

ESTIMATION OF LIPID PROFILE: The blood samples collected from the study and control group were estimated for lipid profile by a routine biochemical Kits methods using ERBA Chem 5+ Semi-automated machine. Estimation of Serum Cholesterol was done by (Enzymatic) Dynamic extended stability CHOD - PAP method, End point with Lipid clearing agent. Serum HDL cholesterol was estimated by Phosphotungstic Acid Method, End Point. Estimation of Serum Triglyceride was done by Dynamic extended stability End point with Lipid clearing agent, Trinder Method. VLDLc and LDLc are calculated parameters and they calculated using Friedwald's Formula, TG/5 where TG is less than $400 \mathrm{mg} / \mathrm{dl}$, LDLc was calculated as : TC (HDLc + VLDLc) these two are calculated parameters. AIP calculated as log (TG/HDLc) when expressed in molar concentration. Conversion factor for Cholesterol $-\mathrm{mg} \% \mathrm{X} 0.026=\mathrm{mmol} / \mathrm{lt}$. Conversion factor for Triglyceride $-\mathrm{mg} \%$ X $0.0113=\mathrm{mmol} / \mathrm{lt}$ (Glycerol phosphate oxidase).

RESULT: As shown in table 1 Serum cholesterol, TG, VLDLc, LDLc and AIP were significantly higher in AMI patients as compared to controls while HDLc was significantly lower in AMI patients as compared to controls.

DISCUSSION: The coronary atherosclerosis is the major cause of IHD, which is chief single cause of death both in developed and developing countries. Early diagnosis of coronary atherosclerosis can reduce the mortality and morbidity. There are several biochemical ratios indicating the risk of atherosclerosis. Gaziano et al reported that the ratio of triglyceride to HDLc was a strong predictor of MI (5). As the search for the risk factor responsible for the CAD goes on many ratio of the lipid have been described as better predictor of CAD. These ratios are total cholesterol / HDLc, LDLc / HDLc and HDLc2 / HDLc3. Result of the Lipid Research Clinics Prevalence Study showed that the ratio of Total Cholesterol / HDLc was better predictor of CAD (6). Tan et al found AIP to be a suitable and statically reliable for evaluating the atherogenicity index (4). Although an independent, inverse relationship between HDLc and cardiovascular risk has been demonstrated beyond any doubt. TG has also been proposed to be a major determinate of cholesterol esterification / Transfer and HDL remodeling in human plasma (7). Fraction etherification rate of cholesterol and ratio of TG / HDLc are powerful predictor of positive finding on coronary angiography (8). The plasma parameter of log ( TG / HDLc) as an atherogenic index has correlation with lipoprotein particle size and esterification rate in apo B lipoprotein depleted plasma ( FER HDL ) (5). There is a high significant association between FER HDL and AIP, suggesting that AIP reflects the delicate metabolic interaction with in the whole lipoprotein complex (9). AIP provides information about the atherogenicity of plasma. Application of AIP to data from earlier trials may offer new insights. The authors, Tan et al should be complimented for evaluating this Atherogenic Index to test it's significance and statistical reliability in a large study with 1669 Diabetic patients (10). Nwagha and Ikekpeazy also reported AI of plasma as an useful predictor of cardiovascular risk among postmenopausal 
women in Enugu, Nigeria (11). They found AIP to be a suitable reliable. AIP may be an important tool for analyzing the results of clinical trials. The association of TGs and HDLc in this simple ratio theoretically reflects the balance risk and protective lipoprotein forces, and both TGs and HDLc are widely measured and available $(12,13)$.

CONCLUSION: Atherogenic Index of plasma can now easily measured in humans and is very useful research tool to assess the effect of risk factors. Although AIP assumes to play a predominant role in evaluation of AMI and developing coronary atherosclerosis, more research is needed on measurement of AIP to be used as clinically useful tool.

Table.1 Lipid profile and Atherogenic index of plasma in patients with AMI and controls.

\begin{tabular}{|l|l|l|}
\hline \multicolumn{1}{|c|}{ Parameter } & \multicolumn{1}{|c|}{ Healthy Control } & AMI Cases \\
\hline Total cholesterol & $145.24 \pm 25.42^{*}$ & $232.04 \pm 65.23^{*}$ \\
\hline Triglyceride & $123.94 \pm 39.38^{*}$ & $206.44 \pm 101.10^{*}$ \\
\hline HDLc & $51.12 \pm 8.45^{*}$ & $30.50 \pm 8.01^{*}$ \\
\hline VLDLc & $24.67 \pm 8.11^{*}$ & $40.08 \pm 20.36^{*}$ \\
\hline LDLc & $91.54 \pm 26.41^{*}$ & $161.10 \pm 61.00^{*}$ \\
\hline AIP & $0.470 \pm 0.308^{*}$ & $0.240 .30^{*}$ \\
\hline
\end{tabular}

* indicates $\mathrm{p}<0.05$.

\# All values were expressed in $\mathrm{mg} / \mathrm{dl} \pm$ SD Number of subjects is 50 . While calculating AIP values were expressed in $\mathrm{mmol} / \mathrm{lt}$.

\section{REFERENCES:}

1. Kundu S C, Bhattachajee T D: Profile in Myocardial Infarction among the rail road workers I Eastern India a 6 year study. Indian H Journal. 1982; 34:151-155.

2. National Cholesterol Education Programme Expert Panel: Expert Panel report on detection, evaluation and treatment of high blood cholesterol in adults. Arch. Inter. Med. 1988; 148: 36-69.

3. Dobiáová M, Frohlich J. The plasma parameter log (TG/HDL-C) as an atherogenic index: correlation with lipoprotein particle size and esterification rate in apoB-lipoproteindepleted plasma (FERHDL). Clin Biochem 2001; 34:583-588.

4. Tan MH, Johns D, Glazer NB. Pioglitazone reduces atherogenic index of plasma in patients with type 2 diabetes. Clin Chem 2004; 50:1184-1188.

5. Gaziano JM, Hennekens CH, O’Donnell CJ, Breslow JL, Buring JE. Fasting triglycerides, high-density lipoprotein, and risk of myocardial infarction. Circulation 1997; 96:25202525.

6. Dobiáová M, Stíbrná J, Pritchard PH, Frohlich J. Cholesterol esterification rate in plasma depleted of very low and low density lipoproteins is controlled by the proportion of HDL2 and HDL3 subclasses: study in hypertensive and normal middle-aged and septuagenarian men. J Lipid Res 1992; 33: 1411-1418. 
7. Frohlich J, Dobiáová M. Fractional esterification rate of cholesterol and ratio of triglycerides to HDL-cholesterol are powerful predictors of positive findings on coronary angiography. Clin Chem 2003; 49:1873-1880.

8. Dobiáová M, Ralová K, Rauchová H, Vohnout B, Ptáková K, Frohlich J. Atherogenic lipoprotein profile in families with and without history of early myocardial infarction; fractional esterification rate of cholesterol in plasma depleted of apoB lipoproteins (FERHDL) and logarithmically transformed ratio of triglycerides to HDL-cholesterol. Physiol Res 2001; 50: 1-8.

9. Dobiáová M. Atherogenic Index of Plasma [Log (Triglycerides/HDL-Cholesterol)]: Theoretical and Practical Implications. Clin. Chem 2004; 50: 1113-1115.

10. Lehto S, Ronnemaa T, Pyorala K, Laakso M. Cardiovascular risk factors clustering with endogenous hyperinsulinaemia predict death from coronary heart disease in patients with type II diabetes. Diabetologia 2000; 43:148-155.

11. Nwagha UI, Ikekpeazy EJ. Atherogenic index of plasma as useful predictor of cardiovascular risk among postmenopausal women in Enugu, Nigeria. Afr. Health Sci 2010; 10(3):248-252.

12. Hokanson JE, Austin MA. Plasma triglyceride level is a risk factor to cardiovascular disease independent of high-density lipoprotein cholesterol level: a meta-analysis of population based prospective studies. J Cardiovasc Risk 1996; 3:213-219.

13. Guérin M, Le Goff W, Lassel TS, Van Tol A, Steiner G, Chapman MJ. Proatherogenic role of elevated CE transfer from HDL to VLDL1 and dense LDL in type 2 diabetes. Arterioscler Thromb Vasc Biol 2001; 21:282-289. 